\title{
Historicidades y discursos históricos. El Partido Aprista Peruano y Socialismo y Participación durante la transición democrática peruana de fines de los años 1970
}

Historicités et discours historiques. Le Partido Aprista Peruano et Socialismo y Participación durant la transition démocratique péruvienne de la fin des années 1970

Historicities and historical discourses. The Partido Aprista Peruano and Socialismo y Participación during the Peruvian democratic transition of the $1970 s$

\section{Daniel Iglesias}

\section{OpenEdition \\ Journals}

Edición electrónica

URL: http://journals.openedition.org/bifea/7981

DOI: 10.4000/bifea.7981

ISSN: 2076-5827

Editor

Institut Français d'Études Andines

Edición impresa

Fecha de publicación: 1 agosto 2016

Paginación: 269-288

ISSN: 0303-7495

Referencia electrónica

Daniel Iglesias, « Historicidades y discursos históricos. El Partido Aprista Peruano y Socialismo y Participación durante la transición democrática peruana de fines de los años 1970 », Bulletin de I'Institut français d'études andines [En línea], 45 (2) | 2016, Publicado el 08 agosto 2016, consultado el 05 noviembre 2020. URL : http://journals.openedition.org/bifea/7981 ; DOI : https://doi.org/10.4000/ bifea.7981

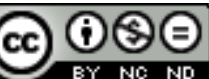

Les contenus du Bulletin de l'Institut français d'études andines sont mis à disposition selon les termes de la licence Creative Commons Attribution - Pas d'Utilisation Commerciale - Pas de Modification 4.0 International. 


\title{
Historicidades y discursos históricos. El Partido Aprista Peruano y Socialismo y Participación durante la transición democrática peruana de fines de los años 1970
}

\author{
Daniel Iglesias*
}

\begin{abstract}
Resumen
Este estudio comparativo examina dos discursos históricos a la luz de sus historicidades. Estudia a la vez la inmersión temporal del discurso memorial del Partido Aprista Peruano y la defensa del legado de la revolución de Juan Velasco Alvarado (1968-1975) por parte de la revista Socialismo y Participación que puede ser vista como una de las vitrinas de la izquierda peruana de tradición marxista. Este trabajo muestra la existencia de diferentes maneras de enraizar la historicidad política que acompañaron las transformaciones institucionales ligadas a la transición democrática peruana.
\end{abstract}

Palabras clave: Partido Aprista Peruano, Socialismo y Participación, revolución, tiempo, historicidad, historia

\section{Historicités et discours historiques. Le Partido Aprista Peruano et Socialismo y Participación durant la transition démocratique péruvienne de la fin des années 1970}

\section{Résumé}

Cette étude comparative se penche sur deux discours historiques à la lumière de leurs historicités. Elle étudie à la fois l'insertion temporelle du discours mémoriel du Partido Aprista Peruano et la défense du legs de la révolution de Juan Velasco Alvarado (1968-1975) par la revue Socialismo y Participación que l'on peut classer comme une vitrine de la gauche péruvienne de tradition marxiste. Ce travail 
montre l'existence de différentes manières d'enraciner l'historicité politique qui accompagnèrent les transformations institutionnelles liées à la transition démocratique péruvienne.

Mots-clés: Partido Aprista Peruano, Socialismo y Participación, révolution, temps, historicité, histoire

\title{
Historicities and historical discourses. The Partido Aprista Peruano and Socialismo y Participación during the Peruvian democratic transition of the 1970s
}

\begin{abstract}
This comparative study examines two historical discourses in the light of their historicities. It studies both the temporal integration of the memorial speech developed by the Peruvian Aprista Party and the defense of the legacy of the Revolution lead by Juan Velasco Alvarado (1968-1975) by the journal Socialismo y Participación, a showcase Peruvian left Marxist tradition. This analysis shows the existence of different ways of linking the political history that accompanied institutional change to the Peruvian democratic transition.
\end{abstract}

Keywords: Partido Aprista Peruano, Socialismo y Participación, revolution, time historicity, history

La mayoría de los discursos políticos de carácter ideológico hacen referencia de una manera u otra al pasado. En el caso de los partidos políticos de izquierda y de las fuerzas revolucionarias del siglo XX, este tipo de movilización del pasado se tradujo, sobremanera, por la celebración discursiva de una serie de héroes fundadores, edades de oro, tiempos gloriosos o hitos históricos. En estos casos, cada partido o publicación revolucionaria poseía y conmemoraba su propio calendario partidario. La historia se inscribía entonces en una historicidad política donde el pasado era canonizado para darle mayor sentido a la trayectoria de la organización. El discurso histórico fortalecía de ese modo la conciencia colectiva a través de pasiones (Ansart, 1998), sentidos (Wolf, 1999) y emociones (Goodwin et al., 2001) que transformaban la historia en memoria.

En momentos de grandes cambios institucionales, los rituales de poder en torno al pasado suelen ser movilizados por los actores que buscan intensificar la politización dentro y fuera de sus grupos de afiliación. Durante los procesos de democratización como en el caso peruano de los años 1977-1980, este tipo de fenómenos tienden a incrementarse aún más ya que forman parte de las batallas políticas que se dan por el control institucional. Es ahí donde la utilización política del pasado (Hartog \& Revel, 2001) se transforma en un componente estratégico de las luchas de legitimidad que movilizan tanto capitales políticos como recursos intelectuales.

En el Perú contemporáneo, varios partidos políticos se han atribuido una naturaleza revolucionaria y han desarrollado un lenguaje afín a los metadiscursos revolucionarios del siglo pasado. Ya sea el Partido Aprista Peruano (PAP), la revista Socialismo y Participación o el propio Sendero Luminoso, estas organizaciones 
inscribían su accionar en una vasta cronología que remontaba al pasado colonial. Se trataba de mostrar las raíces de las injusticias, desigualdades y explotación de las cuales era víctima el pueblo peruano para así señalar la ruptura histórica que ellos representaban. En estos casos, la articulación en los discursos entre el pasado, el presente y el futuro tenía una acuidad muy significativa ya que la urgencia de la lucha revolucionaria transformaba el pasado en historia y en herramienta de poder para construir un futuro político. El tiempo desempeñaba así un papel ideológico que no solamente vehiculaba una conciencia sobre las luchas presentes, sino que también transformaba el pasado en «sujeto político». En las palabras de Anthony Giddens, este tipo de tiempos políticos poseía una dimensión temporal e ideológica tan marcada que su historicidad puede ser vista como «la utilización del pasado para moldear mejor el presente» (Giddens, 1990: 54).

A pesar de la existencia de una sólida tradición de utilización política del pasado por parte de la izquierda peruana, este tipo de cultura política ha sido poco estudiado en las Ciencias Sociales. Los trabajos sobre ritos, culturas o lenguajes políticos no ocupan en efecto un lugar muy importante en la historiografía sobre el siglo XX. Este campo de conocimiento parece haber sido reservado al período colonial o independentista donde sí existen excelentes trabajos sobre ritos de poder (Otemberg, 2012), ceremonias reales (Périssat, 2002), política y cultura (Peralta, 2002) o símbolos de poder (Mujica, 2006). La historia contemporánea de la construcción de las culturas y de las historicidades políticas en el Perú está por lo tanto aún por escribirse. A pesar de este retraso, existen valiosos trabajos que abogaron por una mayor comprensión de la naturaleza simbólica de las acciones colectivas nacionales. Los trabajos de Imelda Vega Centeno (1986) en los años 1980 sobre la cultura popular del PAP renovaron, por ejemplo, nuestro conocimiento sobre el carácter vertical de la militancia aprista y mostraron que una sociología de la militancia política podía sacar a la luz los mecanismos de diferenciación que le dan vida a la politización partidaria. Estos estudios comprobaron asimismo la importancia de los imaginarios políticos como factor de sociabilidad política, así como los efectos residuales de la desigualdad de capitales políticos que existía dentro del PAP.

El campo de conocimiento sobre la construcción de las identidades políticas en el Perú se encuentra actualmente frente a nuevos desafíos y objetos. Como lo prueban los recientes trabajos de Gonzalo Portocarrero (2012), existen nuevas corrientes metodológicas y referencias teóricas que podrían ser movilizadas para recuperar el tiempo perdido. Estas perspectivas, por ejemplo, basan sus explicaciones en una lectura sociológica que no solamente detalla cómo los actores negocian las identidades fabricadas, sino que también hace prevalecer una visión antiesencialista de la política. El presente artículo retoma algunos elementos metodológicos de dichas propuestas, sobre todo su voluntad de explicitar las dinámicas que le dan vida a una cultura política. Sin embargo, este trabajo no se limita a un análisis comparativo de dos discursos históricos, sino que también opta por un enfoque que explicita la historicidad de sus prácticas memoriales. Trata de ver cómo el pasado transformado en memoria participa 
en la construcción de normas institucionales que imponen verdades históricas. En el caso del PAP, en particular, esto significa interrogarse sobre la inmersión de este partido en la temporalidad peruana de fines de los años 1970 y averiguar si esta formación era todavía capaz de crear mecanismos internos de distinción (Bourdieu, 1979) frente a sus rivales. Nuestro objetivo es por consiguiente doble. Por un lado, buscamos reflexionar sobre la historicidad de dos discursos históricos de connotada naturaleza ideológica y, por otro lado, intentamos mostrar ciertas características de las lecturas del tiempo que se desarrollaron durante un período de cambio institucional.

\section{COMPRENDER LA TRANSICIÓN DEMOCRÁTICA PERUANA A LA LUZ DE LA HISTORICIDAD}

La transición democrática peruana de fines de los años 1970 es tradicionalmente interpretada como una secuencia histórica que introdujo un nuevo e incompleto sistema político en el Perú (Mauceri, 1997). Los principales estudios (Booth \& Sorj, 1983) concuerdan incluso en que este período albergó un proceso de negociación extremadamente resguardado por el ejército que tuvo serias dificultades para resolver la crisis económica y social en la cual se encontraba el país. A pesar de su limitada importancia historiográfica, este corto lapso de menos de tres años es considerado como un acto fundacional de la democracia peruana. Ahora bien, la mayoría de las propuestas tienden cuasi exclusivamente a analizar este cambio institucional como un mecanismo político llevado a cabo por un régimen que derrocó un gobierno revolucionario (Chaplin, 1979). En efecto, los análisis se centran en el carácter político de este proceso y sitúan la campaña electoral para una Asamblea Constituyente de 1978 dentro de una temporalidad política que permitió la modernización de las prácticas políticas nacionales. Por ejemplo, el diálogo que se estableció entre nuevas (Alan García del PAP, Xavier Barrón del Partido Popular Cristiano o Javier Diez Canseco de Unidad Democrática Popular) y consolidadas figuras políticas (Haya de la Torre del PAP, Bedoya del PPC, etc.) es leído como parte de un cambio institucional más amplio que fue clave para la construcción de una nueva institucionalidad durante un período de crisis. Según estas lecturas, este entendimiento fue el producto de una ligera apertura del régimen de Morales Bermúdez que permitió la emergencia de un nuevo orden institucional donde la violencia y el orden social debían ser resguardados por un marco constitucional capaz de garantizar una estabilidad a largo plazo.

Este tipo de procesos institucionales es estudiado principalmente por la ciencia política. En el caso particular del Perú, el análisis de su transición democrática nos confronta al problema de la utilidad heurística de la palabra «crisis» para entender los procesos políticos nacionales, puesto que las crisis políticas peruanas no son el fruto de una desregulación del sistema político (Dobry, 1986) sino más bien una variante institucional dentro de una sociedad profundamente desigual. Existe para ello una serie de enfoques sobre transiciones democráticas (Linz \& Stepan, 1996) que permiten examinar la modificación progresiva de los componentes de los 
sistemas políticos. Sin embargo, vale la pena recalcar que tanto la ciencia política como la historia le restan importancia a los «regímenes de historicidad» (Hartog, 2012: 15) que influyen sobre las acciones políticas durante este tipo de período o que tienen un impacto directo sobre la percepción del tiempo por parte de los distintos actores que llevan a cabo las transiciones democráticas. Esto significa que no se interrogan sobre la interiorización del tiempo por parte de los actores tanto en sus prácticas como en sus discursos, sino que reproducen más bien las categorías de análisis sobre el tiempo a su disposición. En lo que concierne a las narrativas históricas sobre la transición democrática peruana, esto tiene como principal consecuencia que las interpretaciones se sumen a una historicidad preexistente nacional donde el tiempo es percibido como un horizonte lejano que agregó negativamente distintos períodos desde la era precolonial hasta la actualidad. Desde luego, la historiografía no logra producir un conocimiento social «carente de cualquier presuposición» (Weber, 1965: 162) ya que su reproducción de esta presuposición histórica afecta su visión de este período histórico en término de ciclos, rupturas, continuidades o discontinuidades. Asimismo, su sujeción a una temporalidad dominada por la clásica distinción «período preinca, inca, colonial, republicano» frena su compresión histórica en términos de temporalidades debido al peso que tiene la linealidad de la narrativa nacional. Finalmente, todos estos elementos condicionan en gran medida el trabajo de historización (Ricœur, 1991) realizado por la disciplina histórica a tal punto que los análisis históricos suelen depender mucho de las pautas referenciales impuestas por una visión unilateral del tiempo que influencia de manera determinante las lecturas históricas de carácter universitario, ideológico o político.

La falta de interés por los «regímenes de historicidad» en vigor durante las transiciones democráticas no solo afecta la capacidad de la historia para comprender mejor el carácter multifacético de su temporalidad. Influye también sobre su facultad analítica, sobre fuentes de este período, en la medida en que todo discurso posee su propia historicidad (Koselleck, 1990). En efecto, como lo demuestra muy bien Jacques Revel, un discurso es parte de una «experiencia del tiempo histórico» (Revel, 2000: 16-17) ya que se inscribe en un marco temporal dado y, por consiguiente, no es ajeno a las apreciaciones morales que se desarrollan durante su tiempo de gestación. Esto significa que los discursos reproducen los procesos sociológicos de su época debido a que sus autores se posicionan en permanencia frente al tiempo (pasado-presente-futuro) según las representaciones sociales a su disposición. Para quienes movilizan este tipo de herramientas, la historicidad es, por lo tanto, algo más que «la relación que tienen los seres humanos con el pasado y el futuro» (Lefort, 2000: 65). Se trata más bien de la capacidad que tienen los actores de una sociedad o de una comunidad de inscribir su accionar en la historia, de su manera de pensar el tiempo así como su capacidad de crear narrativas sobre el tiempo. Supone por consiguiente una conciencia histórica y una inmersión temporal por parte de los actores.

Como toda herramienta heurística, la noción de «régimen de historicidad» posee tanto virtudes como limitaciones. Se trata antes que nada de un término que sirve para comprender mejor no tanto el tiempo o los tiempos históricos, sino sobre 
todo las manifestaciones concretas que derivan de crisis que influyen sobre la articulación entre el pasado, el presente y el futuro. Si tenemos en cuenta que la historicidad puede ser analizada como el punto de intersección entre el campo de experiencia y el horizonte de espera de los actores, existe una serie de eventos históricos que podrían ser reinterpretados mediante esta matriz. Las transiciones democráticas son, por ejemplo, un excelente arquetipo de estas manifestaciones. Poseen en efecto características temporales que transforman estos momentos de cambio institucional en períodos orientados hacia el futuro y el progreso mediante una articulación entre el pasado, el presente y el futuro. Esto se da en particular durante la redacción de las constituciones que son procesos que implican insertarse en el tiempo con el fin de proyectarse hacia el futuro de un país. Desde el punto de vista de su inserción en una lógica temporal, este proceso legal es incluso interpretado la mayoría de las veces por los redactores y políticos como el principio de una nueva era y como un momento de ruptura histórica. La Constitución peruana de 1979 fue elaborada bajo los signos del «progreso» y de un cierto optimismo histórico que fue luego traspasado a la Carta Magna en tanto se buscaba imponer una institución reguladora del orden social mediante el accionar del Estado. Fruto de la negociación entre todas las fuerzas políticas (salvo el partido Acción Popular del derrocado presidente Belaúnde), los debates constitucionales aludían en ese sentido al pasado nacional como prueba de la voluntad de la clase política de focalizarse en el desarrollo económico mediante el reconocimiento de lo permanente y eterno de la «peruanidad». Esto se debió a que la Asamblea Constitucional contaba con la presencia de políticos tradicionales (PAP, PPC), fuerzas de extrema izquierda, figuras revolucionarias antiguamente proscriptas por los militares y la oligarquía (Haya de la Torre, Hugo Blanco) y dirigentes gremiales (campesinos o sindicales) que compartían la idea de que el pasado debía iluminar el camino hacia el futuro.

\section{LAS HISTORICIDADES POLÍTICAS PERUANAS DE FINES DE LOS AÑOS 1970}

Cuando retrocedemos en el tiempo y analizamos la transición democrática peruana de fines de los años 1970 como marco temporal, nos topamos inmediatamente con dos lecturas contradictorias sobre dicho proceso. Por un lado, encontramos las visiones que resaltan la novedad de esta fase e insisten sobre sus logros como, por ejemplo, la producción de un instrumento regulador (la Constitución) que modernizó el país. Es interesante ver que estas perspectivas no difieren mucho de la interpretación que tenía el propio gobierno de Morales Bermúdez sobre la importancia histórica de este cambio institucional. Para el presidente de entonces, el retorno hacia la democracia no era un «retorno» hacia un sistema preexistente sino, al contrario, una novedad histórica que prolongaba una ruptura mayor: la Revolución peruana nacida del golpe de Estado de 1968.

Dentro de las bases ideológicas que proclamó el Proceso Revolucionario Peruano se estableció como objetivo, lograr una democracia social 
con participación de todos los peruanos. Creadas estas condiciones y oportunidades es así como se entiende el retorno hacia una efectiva y no sólo formal democracia en el Perú. Este es un retorno dentro de una nueva situación, donde ahora hay mayores posibilidades de participación económica y política para las mayorías nacionales, y donde las estructuras que impedían precisamente a los partidos y grupos políticos llevar a la práctica sus promesas de grandes transformaciones, han sido en gran parte eliminadas (Oficina Central de Información, 1978: 31-32).

Por otro lado, tenemos otras miradas que difieren mucho de la posición oficial del gobierno de aquella época que inscribía su accionar hacia el futuro con «todos nuestros hermanos latinoamericanos para construir en el futuro la gran Patria que hemos heredado de nuestros grandes héroes» (Oficina Central de Información, 1978: 45). Se trata mayoritariamente de una interpretación crítica del proceso de transición democrática como una resignación frente a la situación de crisis que atravesaba el Perú. En este caso, el Plan Túpac Amaru y la democratización son severamente acusados de instaurar una nueva temporalidad orientada hacia el futuro a costa de un abandono de la historicidad del proceso revolucionario peruano. Mas allá de las críticas y debates de orden ideológico, cabe mencionar que este posicionamiento tuvo fuerte eco a fines de los años 1970 en las filas de una parte de la izquierda peruana como lo prueba, por ejemplo, la desilusión del Partido Comunista Peruano (PCP), encabezado por su Secretario General, Jorge del Prado Chávez, que insistía en la idea de que la transición democrática iba a producir un nuevo rumbo histórico para el Perú debido a que iba a renegar del pasado y presente anticapitalista del gobierno militar:

El Gobierno incurre, así, en un grave error de proyección histórica, pues la experiencia de los pueblos que luchan por su verdadera independencia, desarrollo y justicia social, ha demostrado que el capitalismo, por muy modernizado que se le conciba, no ofrece solución a los males generados por ese mismo sistema (Comisión Nacional de Propaganda del Partido Comunista del Perú, 1977: 18).

A fines de los años 1970, este tipo de discursos que articulaban pasado-presentefuturo no se encontraban únicamente restringidos al ámbito institucional. Como lo prueban las narrativas históricas de la época que se basaban en la teoría de la dependencia para explicar los procesos históricos o las dinámicas sociales en curso, existía la idea de que era urgente detectar la resurgencia del pasado en la actualidad para imaginar un mejor futuro para el país. Esta historicidad se manifestaba sobre todo en la reedición de los principales textos de los grandes pensadores nacionales (Mariátegui, González Prada, etc.) que debían guiar los grandes cambios sociales. Este fenómeno se vio igualmente reflejado en la publicación de libros de fuerte connotación ideológica, como por ejemplo, El reformismo burgués (1978) dirigido por Mirko Lauer. Es así como se desdibujaba un sentimiento de urgencia frente a la grave crisis que atravesaba el Perú a raíz de la crisis económica. Y en este caso, esta urgencia estaba íntimamente ligada a la política en cuanto existía la creencia de que el Estado y los gobernantes podían resolver los problemas siempre y 
cuando tomaran consciencia de que existía desafortunadamente un continuum histórico desde la Independencia. Precisamente, la comprensión del pasado debía ayudar a la elaboración de la polis deseada por los grandes pensadores nacionales (Mariátegui, González Prada, etc.) y, por lo tanto, era clave para salir de un espacio-tiempo unificado (Anderson, 2006) representado por la suma de fracasos sucesivos que poblaban la historia nacional. Encontramos, por ejemplo, este tipo de inmersiones temporales en los actores políticos que creían en la revolución. Para estos no había en ese sentido ninguna contradicción entre una «concepción doctrinaria del Socialismo Científico, al que consideramos teoría y ciencia de nuestro tiempo» y «una vocación patriótica y realista de la problemática nacional en cada instante» (Comisión Nacional de Propaganda del Partido Comunista del Perú, 1977: 17).

Esta presencia del pasado en el presente no eran únicamente referencias movilizadas por actores específicos en espacios sociales restringidos como, por ejemplo, la clase política o el campo intelectual peruano. Hizo también resurgir eventos históricos como recuerdos vividos y como parte de una memoria colectiva a una escala mucho mayor. Prueba de ello fue la manera cómo estas formas de inmersión en el tiempo lograron afectar la percepción del tiempo en sectores informados que participaron por primera vez en una campaña electoral moderna como fue el caso de 1978. Sin poder entrar en detalles debido a la falta de espacio, vale la pena mencionar dos grandes impactos de la inmersión de la sociedad peruana en una historicidad tan marcada. Primero, la elección de la Constituyente demostró que los partidos políticos como el Partido Aprista Peruano (PAP) o la constelación de partidos de izquierda que movilizaron temas del pasado tenían cierta importancia político-social a pesar de que la democracia había sido confiscada por los militares desde 1968. Por otra parte, la alta votación de agrupaciones como el PAP o el PPC confirmó que los partidos tradicionales poseían una fuerza mediadora a nivel social y que la representación política seguía usando los canales simbólicos previos al golpe militar de Velasco Alvarado. Segundo, el alto voto de los partidos que hicieron campaña en torno a la historicidad revolucionaria o que defendían el legado del gobierno de Velasco demostró que existía un interés por las temáticas antiimperialistas en el país. Este voto mostró también que la simbología asociada a dicha postura ideológica se mantenía presente en el espacio público. Por consiguiente, poseemos muchos indicios que prueban que el Perú de fines de los años 1970 atravesaba un período muy cargado a nivel de las historicidades, cosa que fue determinante para el desarrollo de universos simbólicos, memorias históricas y distintos registros de escritura.

\section{REGÍMENES DE ETERNIDAD}

El derrocamiento del general Juan Velasco Alvarado en 1975 marcó el fin de un régimen político que tenía una política nacionalista (Philip, 2013) Ilena de referencias al pasado: Túpac Amaru, José Carlos Mariátegui, Manuel González Prada, el incanato, las culturas preincaicas, etc. Fue asimismo un período donde 
el gobierno no dudó en utilizar recursos públicos para poner de manifiesto su calidad de ruptura histórica y política. A pesar del cambio de régimen, la vida política nacional no perdió su dimensión simbólica ni mucho menos su carácter conflictivo en torno a las filiaciones históricas. Al contrario, la muerte del «chino» Velasco promovió nuevas prácticas memoriales que partidos políticos, como el PAP o revistas como Socialismo y Participación, se apresuraron en implementar.

\section{1. «El APRA nunca muere»}

El renacimiento del Partido Aprista Peruano ocurrido durante el gobierno militar no fue únicamente el fruto del desmoronamiento de un régimen que afrontaba una severa crisis económica desde 1973 y que optó por un cambio institucional con el fin de preservar la unidad corporativa del ejército. El partido no solo acompañó este proceso por una política de negociación con las fuerzas armadas para dejar atrás varias décadas de enfrentamiento, sino que también fue el principal artífice de las luchas memoriales que debilitaron el régimen militar. Este proceso comenzó en realidad en 1975 con la publicación o reedición de los testimonios de sus líderes históricos y de los clásicos libros de historia partidaria. Fueron reeditadas clásicas muestras del heroico pasado aprista como por ejemplo Hombres y Rejas de Juan Seoane en 1977 (el hermano del histórico número dos aprista: «el cachorro» Manuel Seoane), el compendio de las Obras Completas de Haya de la Torre (1976-1977), los dos tomos del libro de historia Apuntes para una biografía del APRA de Luis Alberto Sánchez o la visión histórica de los orígenes del partido, Historia del APRA (1919-1945) de Percy Murillo Garaycochea (1976). Esta transmisión del pasado aprista fue puesta en marcha por sus principales cuadros. Fue el resultado de un accionar llevado a cabo por dirigentes políticos que eran conscientes de que su avanzada edad les otorgaba una cierta legitimidad política. Estos apristas percibían asimismo su empresa editorial como el testamento político de la última gran generación política peruana. Las narrativas históricas se centraron en el hombre que encarnaba con mayor fuerza las luchas sociales del aprismo: Víctor Raúl Haya de la Torre. De esta manera se trataba de subrayar la importancia histórica de Haya como líder organizativo y como único guía para la militancia aprista.

Los retratos simbólicos de Haya de la Torre describían al líder aprista como la encarnación de una lucha eterna a favor del pueblo peruano. Se basaban para ello en el dominio de las paradojas esenciales que constituyen toda trayectoria histórica: las discontinuidades, los retrocesos, los errores, etc. Los textos de Sánchez, Murillo Garaycochea o el propio Haya se centraban en efecto en eventos políticos y personales que relataban una excepcionalidad individual continua. Mediante anécdotas, imágenes o vivencias, el personaje histórico de Haya de la Torre aparecía como un modelo de ejecución alcanzable para todo aquel que quisiese seguir sus pasos. A la vez «excepcional» por su legado inmemorial al transcurso de la historia peruana y «normal» por sus acciones cotidianas cercanas 
a las de cualquier peruano de su tiempo, Haya se situaba dentro de la historia y fuera del tiempo inmediato:

Londres, brumoso, helado, empujaba a las gentes dentro de sus casas, en donde calentaba dulcemente el fuego hogareño. Relucían los árboles de Navidad, cuajados de juguetes. Santa Klaus sonreía ecuménico. Navidad, navidad... Sin hogar, pero con fe y alegría íntima, Haya de la Torre volcose sobre su mesa de trabajo, y recibió la navidad de aquel año, ordenando los materiales de su libro «Por la Emancipación de América Latina»... Afuera, nevaba blandamente (Sánchez, 1979: 137).

Por un lado, su participación en las luchas de los años 1920, en la resistencia contra el autoritarismo en el Perú o su inagotable actividad intelectual validaban su rol central dentro del tiempo lineal nacional. Cuando por otro lado, la eternidad de su pensamiento y accionar lo inscribían en un tiempo revolucionario circular que resurgía cada vez que era recordado el inconcluso proceso de desarrollo nacional.

El uso de varias escalas temporales en la narración de la trayectoria de Haya de la Torre se inscribía en un marco cultural cercano a la tradición católica. La narrativa aprista retomaba en efecto las grandes líneas de lecturas institucionales católicas sobre el pasado que habían consolidado el culto de los santos mediante hagiografías que describían «leyendas» que constituían un conjunto memorial o «monumento» (De Certeau, 1975). Por ejemplo, Haya de la Torre aparece en la historiografía aprista a través de tres tipos de figuras constitutivas:

1. El «mártir» del autoritarismo peruano en las narraciones sobre el exilio, la clandestinidad y el encierro.

2. El «pastor» en los recuerdos sobre la fundación del aprismo.

3. El «hombre lleno de virtud» en los textos sobre su vida privada que relatan su infancia, su adolescencia o su edad adulta.

Esto se manifiesta en particular en los relatos sobre la grandeza de su pensamiento que reúnen estas tres características para así poner de manifiesto tanto su originalidad como su universalidad. Por ejemplo, en su prólogo al libro de Murillo Garaycochea que recoge las grandes etapas de la historia del APRA, Andrés Townsend no duda en afirmar que:

Nada ha ocurrido más importante en la historia social y política del Perú en el siglo XX, que la fundación y la presencia del APRA. Haya de la Torre ha sido el primer pensador político de Latinoamérica que forjó una interpretación filosófica de la historia del continente (Murillo Garaycochea, 1976: 11).

Importantes trabajos sobre el aprismo consideran que estos mecanismos de identificación política seguían lógicas espirituales (Pike, 1986) y operaban según modos de transmisión que apelaban a la religiosidad secular. Sin juzgar positiva o negativamente dicho proceso de identificación, podemos mencionar que las narrativas históricas en torno a Haya de la Torre poseen las mismas características ideológicas que los fenómenos estudiados por Charles Péguy en su famosa distinción entre la «mística» y la «política». Tomando como referente el caso del socialismo francés de Jaurès y de Guesde de fines del siglo XIX que lo calificaba 
como «milagroso», Péguy consideraba que existía por un lado la «mística» como dedicación a una alta doctrina por razones espirituales y por otro, la «política» como compromiso. La idea de una eternidad del legado aprista encarnada por la figura de Haya de la Torre se situaba básicamente en el corazón de un compromiso político con una historicidad dada. Se mantenía en efecto relacionada con una temporalidad política y estaba asociada a prácticas memoriales dedicadas a lograr una mayor politización. Por lo tanto, puede ser vista como una adaptación a un contexto histórico así como un uso de «los beneficios de la mística» (Péguy, 1941: 587). Incluso, este trabajo de identificación que consolidó las fronteras partidarias del PAP puede ser visto como una de las tantas expresiones de la «política» que caracterizan la historia de esta organización política nacional.

\section{2. «La última victoria de Velasco»}

Socialismo y Participación salió a la luz en octubre de 1977. Tenía como miembros de su consejo editorial a importantes intelectuales de izquierda, como Héctor Béjar, Carlos Franco, Francisco Guerra García y Federico Velarde. Se trataba de una publicación ideológicamente influenciada por la dictadura de Velasco que se proponía:

expresar la identidad de una posición afirmada en el curso de una revolución nacional transitoriamente interrumpida; revelar el centro temático de una teoría y una práctica profundamente enraizadas en el corazón independiente de cambio social; definir la continuidad de una orientación que dentro o fuera del poder, quiere participar en la laboriosa construcción de un futuro posible, socialista y autogestor, para nuestra patria (Consejo Editorial de Socialismo y Participación, 1977: 5).

Los editores de la revista no dudaron en utilizar los arquetipos de la historia nacional para recordar el legado revolucionario de Velasco. La reforma agraria de 1969 era vista como una ruptura histórica dentro de una temporalidad continua desde la época colonial. En un artículo de Mario Vázquez sobre el significado y los logros de este proceso, el tiempo histórico aparecía por ejemplo como un garante de la legitimidad de este medida revolucionaria puesto que:

Merece resaltar la certidumbre del análisis de situación hecho en el Plan, dado que es sabido que a partir de la Conquista española durante la época colonial y a lo largo del periodo republicano se desenvuelve en el Perú un proceso ininterrumpido de concentración de la propiedad agraria (Vásquez, 1977: 94).

El tiempo de la Conquista era igualmente recordado en otros artículos que pretendían denunciar también los orígenes de la explotación capitalista e imperialista en el país. Este período era desde luego presentado como el principio de una temporalidad funesta para el país que destruyó un mundo antiguo: la comunidad agraria inca, coherente, homogénea e igualitaria que fue reemplazada por un universo socioeconómico injusto y sinónimo de explotación de los indígenas. 
Esta inmersión temporal en un tiempo más remoto tenía una gran afinidad con el tiempo revolucionario ya que formaba parte de una sensibilidad política y de una cultura ideológica que buscaban recuperar la pureza prima de la «peruanidad». El proyecto de Velasco estaba, por lo tanto, asociado a una retrospección. Ciertos posicionamientos de la dictadura velasquista se reclamaban en efecto de una tradición de justicia social e histórica que legitimaba la necesidad de una reforma agraria como un acto de «liberación» de la nación peruana. Lo que valía a nivel agrario valía también a nivel industrial puesto que se trataba de tomar el control de las fuerzas productivas en manos de la oligarquía y del imperialismo. Las medidas de Velasco buscaban de esa manera recuperar los derechos «naturales» del pueblo peruano como quien recupera los bienes de una nación que fue despojada de su propiedad a raíz de una invasión extranjera.

Esta acribida inserción del velasquismo dentro de la historia nacional seguía por otra parte una lógica discursiva centrada en la exposición de la verdadera naturaleza de este proceso revolucionario. A diferencia de otros procesos revolucionarios que buscaban crear un «hombre nuevo» (el fascismo, el estalinismo, la Revolución cultural de Mao), el proyecto de Velasco era resguardado en Socialismo y Participación como una regeneración de la nación peruana mediante la aplicación de medidas socialistas. Según los autores de la revista, este proceso había creado una temporalidad que combinaba a la vez lo inmutable de la historia nacional (tiempo precolonial) y la creencia en un porvenir igualitario inspirado en el horizonte socialista. Su principal aporte había sido por consiguiente el borrar la vieja matriz sedimentaria que obstruía la continuidad de la historia nacional por medio de la eliminación de los antiguos propietarios de los medios de producción.

Esta inmersión en el abismo del tiempo no se oponía a una revisión y posterior explotación del legado de la «Revolución peruana». Si bien los exigentes editores de Socialismo y Participación lamentaban fuertemente la muerte de Velasco en sus editoriales, no silenciaron las críticas que ponían de manifiesto el carácter inconcluso de la revolución. Las páginas de la revista publicaron, por ejemplo, serias críticas sobre los alcances de la reforma agraria que demostraban los límites de una economía planificada y orientada hacia la socialización progresiva de los medios de producción. Sin embargo, cabe mencionar que dichas objeciones nunca pusieron en duda la filiación de la publicación con el velasquismo. En las palabras de sus redactores, estas posiciones debían contribuir más bien a mejorar las condiciones del advenimiento del horizonte socialista en el Perú:

No se trata de ceder frente a las afirmaciones de que el proceso del 68 fue un engaño o una equivocación tras el encubridor argumento de la lucha de tendencias sino de afirmarlo, defenderlo y reivindicarlo (Consejo Editorial de Socialismo y Participación, 1978: 7).

\section{REGÍMENES DE AUTENTICIDAD}

Como todo cambio institucional en un país en crisis, la transición democrática peruana no presentaba mayores garantías de estabilidad política a largo plazo. Se 
trató de un compromiso político conducido por actores que buscaban ponerle fin a los faccionalismos políticos y a las contestaciones sociales. El modelo democrático impuso los ideales de un Estado fuerte y de una soberanía popular heredada de la tradición del Estado-nación. Según esta tradición, los poderes públicos debían guiar el devenir nacional para así frenar la aceleración del tiempo ligada al capitalismo. La Constitución, por ejemplo, nació de una alianza política que asociaba un pasado valorado y un futuro moderno. Esta forma de concientización histórica defendía la idea de progreso, de soberanía territorial y de conciencia nacional unificada. Seguía los grandes parámetros temporales que se habían puesto en marcha a partir de 1968 y que se centraban en la idea de que la nación era el núcleo intemporal de un tiempo «auténtico». Durante el gobierno militar de Velasco, todo lo «auténtico» se refería a todo lo que reflejaba la unidad del pueblo, la cultura y el Estado. Correspondía a una visión del tiempo que le daba a la nación una autoridad moral muy fuerte. Asimismo, se basaba en figuras o instituciones que poseían un valor social tan fuerte que se habían vuelto indispensables para asegurar la soberanía interna y externa del Perú. Estos mecanismos de diferenciación e identificación marcaron pautas temporales que fueron luego movilizadas por otras narraciones históricas durante el gobierno de Morales Bermúdez en 1975.

\section{1. «Tatuaremos con sangre en la historia. Nuestra huella pujante y triunfal»}

La «autenticidad» y la «eternidad» forman parte de los elementos constitutivos de la ideología. Sin embargo, el régimen de «autenticidad»se diferencia del régimen de «eternidad» en un punto fundamental. Este régimen acepta en efecto el paso del tiempo y se focaliza en la historia como una herramienta de la identidad política. La publicación de Obras Completas del viejo líder aprista, Haya de la Torre, puede ser vista en ese sentido como el punto culminante de la búsqueda de «autenticidad» por parte del Partido Aprista Peruano. Editada en 1977 cuando su autor era la personalidad política más importante del país a raíz de su abrumadora votación en las elecciones a la Constituyente, esta obra prolongó la vasta operación de desmitificación puesta en marcha por Luis Alberto Sánchez con la publicación de sus escritos sobre la historia del PAP. La visión histórica de Sánchez interpretaba el pasado del aprismo y buscaba contradecir los prejuicios de los cuales era víctima el partido. Se trataba de mostrar que el PAP no había sido una organización violenta sujeta a intereses extranjeros o elitistas y que los errores que se le imputaban no eran más que calumnias que se remontaban a los eventos de la llamada «Revolución aprista de Trujillo de 1932» (Giesecke, 2010). Según Sánchez, el PAP no había sido responsable de la violencia ocurrida durante dicha insurrección popular. Los cuadros del partido no habían alentado el desorden y los actos violentos que provocaron la fuerte represión política (miles de muertos) que se desató como respuesta del ejército a la ejecución de oficiales por parte de la comuna insurreccional trujillana. Para los apristas, las acciones llevadas a cabo 
en Trujillo eran el sello al contrario de una rebelión espontánea y muy localizada ,ajena a la cúpula aprista.

Los escritos sobre el pasado del PAP buscaban recalcar las filiaciones que tenía el partido con grandes eventos culturales y populares como por ejemplo la Revolución mexicana, la reforma universitaria de Córdoba o las luchas estudiantiles contra el régimen de Leguía (1919-1930). Esta exposición de la génesis del aprismo se centraba principalmente en la temática de la juventud del movimiento y su carácter de novedad ideológica durante los años 1920: «primera revolución social o socialista del siglo XX» (Murillo Garaycochea, 1976: 18). La reforma universitaria de Córdoba en particular servía para demostrar la legitimidad revolucionaria del aprismo, contribuyendo así al desarrollo de una estructura socioafectiva que llevaba casi 40 años (Iglesias, 2013) perfeccionándose. Esta memoria partidaria se caracterizaba por hacer dialogar dos temáticas muy cargadas simbólicamente: por un lado, un culto al Jefe (Haya de la Torre) y, por el otro, la creencia de que el partido encarnaba al pueblo peruano. Borrando los orígenes marxistas de la Alianza Popular Revolucionaria Americana (APRA) y optando por una celebración de su carácter social, esta visión del pasado le otorgaba al PAP el estatus de heredero de luchas sociales que atravesaron fronteras.

En las Obras Completas de Haya de la Torre, este tipo de filiaciones se manifestaba aún más. Compendio de artículos publicados a lo largo de los años en distintos periódicos o revistas, este libro se focalizaba sobre todo en las luchas sociales previas a la llegada al poder de Leguía, así como en los lazos de amistad que unían al líder aprista con figuras de gran legitimidad histórica como por ejemplo Manuel González Prada. El texto «La jornada de las 8 horas», inicialmente publicado en 1941 en la revista clandestina Lecturas Obreras, es por ejemplo una clarísima muestra de dicha voluntad de crear un continuum entre los años 1970 y un pasado presentado como la «Edad de oro» de las luchas sociales. En esta narración, Haya de la Torre subrayaba que fueron los estudiantes quienes permitieron la conquista social que estableció la jornada de 8 horas de trabajo en el Perú. Haya utilizaba para ello una escritura a fuerte connotación dramática e incluso teatral, donde la utilización de diálogos u otros recursos literarios le permitía al autor personificar la acción colectiva. El narrador aparecía entonces siempre en el centro de la acción y de la lucha. En ciertos episodios, él maniobraba las turbas de descamisados en cólera que se enfrentaban a la violencia policial cuando no era, en otros, el principal negociador frente a las autoridades competentes. La complejidad de los hechos pasaba por consiguiente a un segundo plano. Se trataba más bien de movilizar los registros clásicos de la escritura histórica peruana, donde la historia es una narración que resalta los actos heroicos de grandes figuras casi legendarias.

Por otra parte, la historiografía aprista buscaba relevar históricamente el sufrimiento y el dolor que vivieron en carne propia los militantes a lo largo de los años de represión, encierro y persecución política. La reedición del libro de Seoane, Hombres y Rejas, jugó aquí un papel simbólico muy fuerte puesto que este texto expone minuciosamente una experiencia subjetiva en las cárceles bajo el régimen autoritario de Oscar Benavides (1933-1939). Escrita en 1935, cuando su autor 
estaba a punto de ser ejecutado por el gobierno, esta obra narra condiciones de detención así como los efectos psicológicos del encierro:

El trabajo mental deja abundancia de energías sin empleo. Adentro de nosotros el instinto se vitaliza en ellas. Es la tormenta en los sentidos. Las vísceras se agitan y el ancestro presiona con su empuje avasallante. La raíz de la vida lanza la prepotencia de su chorro en un impulso que llega hasta la piel sensible y en la noche se nos prende la carne como una llamarada. Del sexo al corazón nos retuerce la angustia. La angustia es un pabilo por el que corre como fuego el deseo. La imposibilidad de calma nos lacera la carne con estrujones de desesperación y la vida desgarra con sus ansias nuestra paz. Grita la especie en nuestros cuerpos su voz insatisfecha (Seoane, 1977: 192).

Su narrativa histórica exalta principalmente un pasado combativo que demostraba el sacrificio consentido por el PAP en nombre de la nación y del pueblo peruano. A través de un relato accesible al lector debido a una personificación de una realidad histórica palpable, se centra en la importancia del sacrificio personal en nombre de ideales políticos. Para Manuel Seoane, este sacrificio conformaba la base de un deber político en nombre del Perú. Fruto de una cultura organizativa establecida a lo largo de los años, su narración repetía por consiguiente las enseñanzas de un partido que buscaba subrayar su legitimidad histórica a través de distintos recursos. Este tipo de relatos cimentaba, por ejemplo, los afectos colectivos al interior del PAP gracias a un fenómeno de identificación directo con el aprista perseguido y torturado, cuando no con un líder como Haya de la Torre cuya trayectoria era recordada mediante una memoria que aspiraba a darle a todos la sensación de ser parte de una historia legítima.

\section{2. El antiimperialismo peruano: una herencia en disputa}

El trabajo de ejemplificación de figuras históricas constituye uno de los motores de los procesos políticos que buscan consolidar memorias oficiales. Apoyándose en la singularidad y ejemplaridad de ilustres personajes, esta práctica política consiste en proyectar sobre el presente la legitimidad de aquellos que gozan de una cierta aceptación social. Esta exposición de las cualidades, títulos o virtudes de grandes figuras históricas, sin embargo, no es sistemática. Se adapta en la mayoría de los casos a exigencias situacionales como por ejemplo la urgencia de la muerte de un líder caudillista, de una campaña electoral no prevista o el advenimiento de una dictadura. Esta introducción de una nueva temporalidad en el presente político revaloriza entonces los capitales simbólicos existentes mediante nuevas imágenes o palabras que le dan mayor vitalidad a las «guerras de las identidades». En el caso peruano, la muerte de Velasco Alvarado provocó la resurgencia de una pluralidad de voces en la izquierda peruana que defendían la necesidad de recurrir al pasado. Muchas de estas expresiones retomaron los principales elementos de la mitología de tradición marxista-leninista donde los «semi-dioses» (Khapaeva 
\& Kopossov, 1992) participan en la edificación de un sistema de identificación política. La particularidad de Socialismo y Participación fue la reutilización de la figura de Mariátegui no solamente en su calidad de precursor ideológico, sino también como garante de la legitimidad histórica de la «Revolución nacional».

El panteón secular de esta tradición cultural era coherente y estructurado. Apelaba a distintos personajes históricos que eran progresivamente integrados a la concientización histórica en torno al gobierno de Velasco. Su principal figura, José Carlos Mariátegui, aparecía como un precursor del régimen militar mediante artículos que buscaban que el lector politizado pudiese identificarse aún más con su comunidad política. En un artículo titulado «Mariátegui y los orígenes del marxismo latinoamericano», el pensador marxista argentino José Aricó insistía, por ejemplo, en la singularidad ideológica del precursor de las medidas de integración del Indio a la nación puestas en marcha por la dictadura de Velasco. Según Aricó, Mariátegui había sido el primer intelectual peruano que había emancipado culturalmente al pueblo de la oligarquía. Había renovado el conocimiento sobre las condiciones sociales del mundo rural gracias a una mirada crítica que le había permitido ver la conciencia revolucionaria de las clases oprimidas. En Socialismo y Participación, la figura de Mariátegui cumplía por consiguiente una función ilustrativa y pedagógica del carácter nacional de las medidas sociales tomadas bajo la dictadura. Era el garante de la autenticidad histórica de un proceso revolucionario que instauró un proceso de recuperación de la identidad peruana mediante medidas sociales como la reforma agraria de 1969 que hizo que los indios pudiesen disponer de sus tierras.

La repartición de roles entre personajes mitológicos era organizada según las principales características del régimen de Velasco Alvarado. La especialización de Mariátegui era percibida a través de la exposición de su originalidad ideológica en comparación con los paradigmas marxistas y del pensamiento de Haya de la Torre. Esta diferenciación resaltaba el coraje y la excelencia moral de este «héroe» revolucionario como prueba de su gran competencia intelectual. Por ejemplo, su filiación con Manuel González Prada tomaba a contra-pie la tradición aprista y declaraba que Mariátegui había sido el único heredero de este gran intelectual peruano. Para la revista, el fundador de la revista Amauta había modernizado y mejorado las ideas de González Prada sobre la nación peruana a partir de nuevos parámetros más adaptados a la realidad nacional. Para José Aricó, el libro Siete ensayos sobre la realidad nacional de Mariátegui (1928) había significado «el mayor esfuerzo teórico realizado en América Latina por introducir una crítica socialista de los problemas y de la historia de una sociedad concreta y determinada» (Aricó, 1978: 33).

Si la elaboración del sistema mitológico puesto en marcha por Socialismo y Participación databa de fines de los años 1970, gran parte de sus lineamientos ideológicos eran más antiguos. Estos se habían ido formando a lo largo del siglo XX paralelamente a la evolución de la rivalidad entre el Partido Aprista Peruano y la izquierda de tradición marxista. La muerte de Mariátegui en 1930 fue el punto de partida de un esquema de politización dibujado por sus seguidores entre los cuales 
destacaba especialmente el antiguo jefe de la sección parisina del APRA, Eudocio Ravines. Este episodio inauguró la larga tradición de enemistad con el aprismo que la revista no dudó en poner de manifiesto. Esta rivalidad se basaba en la disputa de los orígenes del antiimperialismo peruano. Jerarquizando los orígenes del pensamiento que había inspirado el gobierno de Velasco, Socialismo y Participación profundizó este tema alegando que el nacimiento del PAP había significado el fin de un proceso revolucionario peruano con grandes potencialidades. En un texto teórico sobre las diferencias doctrinarias entre el pensamiento aprista y las ideas de Mariátegui en los años 1920, Carlos Franco (1979) consideraba, por ejemplo, que si bien estas dos corrientes habían compartido la misma visión de la actividad política, las propuestas del fundador de Amauta tenían realmente en cuenta las características sociales y espaciales de las relaciones productivas en el país. Por lo tanto, esta perspectiva no había perdido su vigor debido a que las asimetrías de las relaciones sociales se mantenían aún vigentes en el país. En otras palabras, el legado de Mariátegui seguía vigente puesto que subraya continuidades en la larga duración de la historia nacional a pesar de los cambios introducidos por una revolución que no pudo concretar del todo sus objetivos socioeconómicos.

\section{CONCLUSIÓN}

¿Qué revelan las narrativas históricas propuestas por estos dos campos políticos rivales? Indican en primer lugar que existía una correlación muy fuerte durante la transición democrática entre el contexto de cambio institucional y los regímenes de historicidad que incitaban a producir o reproducir nuevas temporalidades. En todos los ejemplos encontramos dos axiomas que reflejaban los fundamentos de la conciencia histórica y nacional peruana. Por una parte, ciertos eventos o figuras históricas eran reintroducidos en el espacio público como tangente que recordaba las continuidades temporales de las luchas sociales en nombre de la nación. Por otra parte, la reintroducción de temáticas revolucionarias (el horizonte del Estado socialista y el horizonte aprista de la justicia social) confortaban una visión lineal de una historia proyectada hacia el futuro. La orientación temporal centrada en el futuro del Perú aseguraba de esta manera una legitimidad a la política como herramienta al servicio del Estado-nación, de un ideal progresista así como de un pasado inscrito con letras de nobleza en el presente.

En estas configuraciones de saberes revolucionarios, el tiempo mantenía a la vez reflejos de preservación frente a un presente incierto y las creencias en los mitos sagrados de una temporalidad nacional peruana. Reflejaba la preeminencia de historicidades nacionales que poseían ciertos rasgos de una filosofía mesiánica y revolucionaria de la historia. Podemos pensar, por lo tanto, que existía todavía a fines de los años 1970 en el Perú historicidades políticas que pueden ser interpretadas según los preceptos de Walter Benjamin (2000), enunciados en sus célebres escritos sobre el tiempo y la historia. El nacionalismo histórico defendido por las dos corrientes políticas estudiadas reproducía en efecto ciertos rasgos de una visión mesiánica del tiempo que se situaba, según Benjamin, en el corazón 
del tiempo y de la historia. Dado los orígenes románticos del modelo nacional que fue introducido y perfeccionado en el Perú desde el siglo XIX, podemos pensar que existen indicios que podrían probar que estas visiones veían el futuro nacional como el cumplimiento de los lineamientos de la modernidad. Por otra parte, cabe recalcar que los posicionamientos teleológicos apristas y marxistas se inscribían en la larga tradición del materialismo histórico en el Perú. Volviendo a Benjamin, estas raíces intelectuales del pensamiento antiimperialista peruano se beneficiarían con un análisis a través del «concepto de historia» benjaminiano que posee un valor heurístico reconocido en el estudio de la correspondencia entre lo «sagrado» y lo «profano», la «teología» y la «política» e incluso entre la «temporalidad mesiánica» y la «historicidad revolucionaria».

\section{Referencias citadas}

ANDERSON, B., 2006 - L'Imaginaire national : réflexions sur l'origine et l'essor du nationalisme, 224 pp.; París: La Découverte.

ANSART, P., 1998 - La gestion des passions politiques, 204 pp.; París: L'âge d'homme.

ARICÓ, J., 1978 - Mariátegui y los orígenes del marxismo latinoamericano. Socialismo y Participacion, $\mathbf{n .}^{\circ}$ 5: 13-43.

BENJAMIN, W., 2000 - Oeuvres I, 400 pp.; París: Gallimard.

BOOTH, D. \& SORJ, B. (eds.), 1983 - Military Reformism and Social Classes. The Peruvian Experience, 1968-1980, xiii + 210 pp.; London: Macmillan Press.

BOURDIEU, P., 1979 - La Distinction : critique sociale du jugement, 670 pp.; París: Éditions de Minuit.

CHAPLIN, D. (ed.), 1979 - Peruvian Nationalism: A corporatist Revolution, 600 pp.; New Brunswick: Transaction Press.

COMISIÓN NACIONAL DE PROPAGANDA DEL PARTIDO COMUNISTA DEL PERÚ, 1977 - Lo que planteó el PCP al presidente Morales Bermúdez, 84 pp.; Lima: Humboldt S.A.

CONSEJO EDITORIAL DE SOCIALISMO Y PARTICIPACIÓN, 1977 - Hacia una izquierda socialista, nacional y popular. Socialismo y Participación, $\mathbf{n}{ }^{\circ}$ 1: 7-33.

CONSEJO EDITORIAL DE SOCIALISMO Y PARTICIPACIÓN, 1978 - La última Victoria de Velasco. Socialismo y Participación, n. ${ }^{\circ}$ 2: 5-8.

DE CERTEAU, M., 1975 - L'écriture de l'histoire, 358 pp.; París: Gallimard.

DOBRY, M., 1986 - Sociologie des crises politiques : la dynamique des mobilisations multisectorielles, xlv + 383 pp.; París: Presses de la Fondation nationale des sciences politiques.

FRANCO, C., 1979 - Mariategui y Haya: Surgimiento de la izquierda nacional. Socialismo y Participacion, $\mathbf{n .}^{\circ} \mathbf{8}$ : 11-43.

GIDDENS, A., 1990 - The Consequences of Modernity, ix + 186 pp.; Stanford: Stanford University Press.

GIESECKE, M., 2010 - La insurrección de Trujillo, 7 de junio de 1932, 371 pp.; Lima: Fondo Editorial del Congreso del Perú. 
El PAP y Socialismo y Participación durante la transición democrática peruana de fines de los años 1970

GOODWIN, J., JASPER, J. \& POLLETA, F., 2001 - Passionate Politics. Emotions and social movements, xii +370 pp.; Chicago: The University of Chicago Press.

HARTOG, F., 2012 - Régimes d'historicité. Présentisme et expériences du temps, 257 pp.; París: Seuil.

HARTOG, F. \& REVEL, J. (eds.), 2001 - Les usages politiques du passé, 206 pp.; París: Éditions de l'École des hautes études en sciences sociales.

HAYA DE LA TORRE, V. R., 1976-1977 - Obras Completas, 7 tomos; Lima: LibreríaEditorial Juan Mejía Baca.

IGLESIAS, D., 2013 - Les mythes fondateurs du Parti Apriste Péruvien. Sociohistoire de la culture politique d'un parti latino-américain (1923-1980), 132 pp.; París: Éditions de l'Institut des Hautes Études de l'Amérique Latine.

KHAPAEVA, D. \& KOPOSSOV, N., 1992 - Les demi-dieux de la mythologie soviétique. Études sur les représentations collectives de I'histoire. Annales. Economies, Sociétés et Civilisations, 47 (4): 963-987.

KOSELLECK, R., 1990 - Le futur passé : contributions à la sémantique des temps historiques, 334 pp.; París: Éditions de l'École des hautes études en sciences sociales.

LAUER, M., 1978 - El reformismo burgués, 254 pp.; Lima: Mosca Azul Editores.

LEFORT, C., 2000 - Les formes de I'histoire : essais d'anthropologie politique, 568 pp.; París: Gallimard.

LINZ, J. \& STEPAN, A., 1996 - Problems of democratic transition and consolidation: southern Europe, South America and post-communist Europe, xx + 479 pp.; Baltimore: John Hopkins University Press.

MAUCERI, P., 1997 - The Transition to «Democracy» and the Failures of Institutions Building. In: The Peruvian Labyrinth: polity, society, economy (M. Cameron \& P. Mauceri, eds.): 13-37; University Park, Pennsylvania: The Pennsylvania State University Press.

MARIÁTEGUI, J. C., 1928 - Siete ensayos sobre la realidad nacional, 351 pp.; Lima: Editora Atahualpa.

MUJICA, V. (ed.), 2006 - Visión y Símbolos. Del Virreinato criollo a la república peruana, xvii + 367 pp.; Lima: Banco de Crédito.

MURILLO GARAYCOCHEA, P., 1976 - Historia del APRA (1919-1945), 498 pp.; Lima: Editor Enrique Delgado Valenzuela.

OFICINA CENTRAL DE INFORMACIÓN, 1978 - La Revolución Peruana, 41 pp.; Lima: Editora Perú.

OTEMBERG, P., 2012 - Rituels du pouvoir à Lima. De la Monarchie à la République, 285 pp.; París: Éditions de l'École des hautes études en sciences sociales.

PÉGUY, C., 1941 - Oeuvres Complètes, 1908-1914, 20 tomos; París: Gallimard.

PERALTA, V., 2002 - En defensa de la autoridad. Política y cultura bajo el virrey Abascal. Perú 1806-1816, 199 pp.; Madrid: Consejo Superior de Investigaciones Científicas, Instituto de Historia.

PÉRISSAT, K., 2002 - Lima fête ses rois (XVle-XVIIle siècles). Hispanité et américanité dans les cérémonies royales, 318 pp.; París: L’Harmattan.

PHILIP, G., 2013 - Nationalism and The Rise of Peru's General Velasco. Bulletin of Latin American Research, 32 (3): 279-293.

PIKE, F., 1986 - The Politics of the Miraculous in Peru. Haya de la Torre and the Spiritualist Tradition, 391 pp.; Lincoln: University of Nebraska Press.

PORTOCARRERO, G., 2012 - Profetas del odio. Raíces culturales y lideres de Sendero Luminoso, 260 pp.; Lima: Fondo Editorial de la Pontificia Universidad Católica del Perú. 
REVEL, J., 2000 - Pratiques du contemporain et régimes d'historicités. Le Genre Humain, 35: 13-20.

RICOEUR, P., 1991 - Temps et Récit. Le temps raconté, 3 volúmenes; París: Le Seuil.

SÁNCHEZ, L. A, 1978-1982 - Apuntes para una biografía del APRA, 3 tomos; Lima: Mosca Azul Editores.

SÁNCHEZ, L. A, 1979 - Víctor Raúl Haya de la Torre o el político. Crónica de una vida sin tregua, 241 pp.; Lima: Enrique Delgado Valenzuela.

SEOANE, J., 1977 - Hombres y rejas, 239 pp.; Lima: Editorial Galaxia.

VÁZQUEZ, M., 1977 - Significado y logros de la Reforma Agraria peruana. Socialismo y Participación, n. ${ }^{\circ}$ 1: 93-107.

VEGA CENTENO, I., 1986 - Ideología y cultura en el aprismo popular, 132 pp.; Lima: Tarea, Fundación Friedrich Ebert.

WEBER, M., 1965 - Essais sur la théorie de la science, 540 pp.; París: Plon.

WOLF, E., 1999 - Envisioning Power: Ideologies of Dominance and Crisis, xi + 339 pp.; Berkeley: University of California Press. 